\title{
Trends of Public Interest in Sleep Disorders: Looking by Internet Searching Volume
}

\author{
Ki-Hwan Ji, MD, Mi-Ri Kang, MD \\ Department of Neurology, Busan Paik Hospital, Inje University College of Medicine, Busan, Korea
}

Received: November 25, 2017

Revised: December 5, 2017

Accepted: December 5, 2017

Correspondence

Ki-Hwan Ji, MD

Department of Neurology,

Busan Paik Hospital, Inje University

College of Medicine,

75 Bokji-ro, Busanjin-gu,

Busan 47392, Korea

Tel +82-51-890-8613

Fax +82-51-890-6130

E-mail kihwanji@gmail.com

ORCID

Ki-Hwan Ji

https://orcid.org/0000-0002-5371-5398

Mi-Ri Kang

https://orcid.org/0000-0002-9833-023X
Background and Objective To investigate the trends of public interest in the sleep disorders by searching terms in Korea and English-language. Google and Naver offer the tools assessing Internet searching volumes that may represent public interest on search terms.

Methods Search terms were limited to Korean in Naver Trends and English in Google Trends. We use the keywords insomnia, sleep apnea, snoring, restless legs syndrome (RLS). A reference trend of dementia was compared.

Results The median Naver Trends score of insomnia [21.3, interquartile ranges (IQR), 17.926.5] was consistently higher than that of dementia (11.7, IQR, 10.0-13.5), RLS (7.5, IQR, 5.9-9.3), snoring (7.3, IQR, 5.9-10.5) and sleep apnea (1.6, IQR, 1.2-2.0) January 2016-October 2017. The Naver Trends score of sleep disorders decreased over time. The median Google Trends score of dementia (49, IQR, 45-55) was higher than that of sleep apnea (42, IQR, 40-45), insomnia (36, IQR 34-38), snoring (24, IQR 21-28), and RLS (23, IQR, 22-27) January 2004-October 2017. The Google Trends score of snoring and insomnia increased over time, but RLS and sleep apnea decreased over time. However, when we matched the search period with Naver Trends, the trends scores of insomnia, sleep apnea, RLS, and dementia increased over time.

Conclusions The Naver Trends score of insomnia was higher than that of dementia, but those of sleep apnea, RLS was relatively low. To the contrary, the Google Trends score of dementia and sleep apnea was higher than that of insomnia.

Sleep Med Res 2017;8(2):62-67

Key Words Internet, Trend, Sleep disorder, Dementia.

\section{INTRODUCTION}

Sleep medicine has been developing rapidly in recent years. Sleep disorders are linked to various diseases of the human body and risk factor for worsening chronic disease. With the current reports that sleep disorders may occur cardiovascular and brain disease, more public attention is being generated. Through various open activities of the sleep academy in Korea, all efforts are being made to raise public interest in sleep disorders. However, it is not easy to measure changes in the public attention. Korea is a country wherein the Internet service is well-established and popularized. Google and Naver are the most popular Internet search engines in Korea. Google and Naver offer the tools assessing searching volumes; Google Trends and Naver Trends, respectively. Both provide the comparative averages of the search volumes that numbers are representing search interest proportional to the highest point in the chart for the given region and time. With the trend tools, the searching volume for health-related information through the Internet can be tracked. ${ }^{1,2}$ Therefore, we can estimate the public interest in sleep disorders by checking the volume of the Internet searching keywords about sleep disorders. We hypothesize that the Internet searching volume about sleep disorder increases because of expanded public interest on sleep. In this study, we investigate the trends of public interest in sleep disorders and compare with dementia by searching terms in Korea and Eng- 
lish-language.

\section{METHODS}

This study did not involve human participants, and therefore specific ethical approval was not needed. Google Trends and Naver Trends interface were used to obtain search traffic data for representative sleep disorders. We adopt a reference trend with the term of dementia. Our search terms were limited to Korean for the Naver Trends and English for the Google Trends, and searches were conducted on October 20, 2017. We used the keywords of insomnia, sleep apnea, snoring, restless legs syndrome (RLS) in Korean and English. Table 1 includes a full list of the keywords used. Our study's purpose was to measure the relative searching volume of representative sleep disorders with limited keywords but not a comprehensive analysis of Internet searches linking to these conditions or other potential conditions that could impact sleep disorders. Such an investigation was beyond the scope of this study. For each search keyword, weekly search volumes were downloaded in .csv format January 2004-September 2017 with Google Trends and daily search volumes from January 2016-September 2017 with Naver Trends. The Naver Trends provided the information by age groups. It should be noted that Google Trends and Naver Trends provide only relative data, not the absolute number of searches for each term. Both give a number between 0 to 100 , and a value of 100 is the peak popularity of the term. Therefore, a value of 50 means that the term is half as popular and a score of 0 indicates the term is less than $1 \%$ as popular as the peak.

\section{Analysis}

Google and Naver Trends score were reported as median and interquartile ranges (IQR). Spearman's correlation between time and trends score was assessed. In Naver Trends, the trends scores of each disease in age group was compared with Wilcoxon signed-rank test, and the trends scores of each disease between two age groups were analyzed with independent t-test or Mann-Whitney test. We used Stata (StataCorp, 2015, Stata Sta- tistical Software: Release 14, College Station, TX, USA) for statistical analysis. Significance was accepted at $\mathrm{p}<0.05$.

\section{RESULTS}

\section{Naver Trends Score of All Age over January 2016- October 2017}

The Naver Trends score of all age showed in Fig. 1. The peak of Naver Trends score was recorded in January 2016 for insomnia. The remaining data were then scaled according to this peak value. The Naver Trends score for insomnia remained substantially higher than that of each of the other disease throughout the search period (i.e., January 2016-September 2017). In a few cases (after May 2017) the number of searches for dementia exceeded those for insomnia. Overall, the median Naver Trends score of insomnia (21.3, IQR, 17.9-26.5) was invariably higher than that of dementia (11.7, IQR, 10.0-13.5), RLS (7.5, IQR, 5.9-9.3), snoring (7.3, IQR, 5.9-10.5) and sleep apnea (1.6, IQR, 1.2-2.0). The Naver Trends score of insomnia and snoring exhibits a highly significant decrease over the time [rho = -0.66 , confidence interval $(\mathrm{CI}),-0.71$ to $-0.61 ; \mathrm{p}=0.001$ and rho $=$ -0.63 , CI, -0.68 to $-0.57 ; \mathrm{p}=0.001$, while that of dementia has remained virtually unchanged ( $r$ o $=-0.001, \mathrm{CI},-0.08$ to $0.07 ; \mathrm{p}=$ 0.85 ), and whereas that of sleep apnea and RLS has displayed a marginally significant decrease, respectively (rho $=-0.28, \mathrm{CI}$, -0.36 to $-0.21 ; \mathrm{p}=0.001$ and $\mathrm{rho}=-0.25, \mathrm{CI},-0.32$ to $-0.17 ; \mathrm{p}=$ $0.001)$.

\section{Naver Trends Score by Age Groups January 2016- October 2017}

Age $<40$ years

The median Naver Trends score of insomnia (48.3, IQR, 39.756.3) was constantly higher than that of dementia (23.4, IQR, 20.0-26.7), snoring (17.6, IQR, 14.2-21.6), RLS (15.0, IQR, 12.7-18.9), and sleep apnea (13.9, IQR, 12.0-15.8).

Table 1. Search strategies

\begin{tabular}{|c|c|c|}
\hline \multirow{2}{*}{ Search reference } & \multicolumn{2}{|c|}{ Search string } \\
\hline & Korean & English \\
\hline Insomnia & 불면증, 불면, 불면증상 & Insomnia \\
\hline Sleep apnea & $\begin{array}{l}\text { 수면무호흡, 무호흡, 폐쇄성수면무호흡, 수면무호흡증, } \\
\text { 무호흡증, 폐쇄성수면무호흡증, 수면무호흡증후군, } \\
\text { 무호흡증후군, 폐쇄성수면무호흡증후군 }\end{array}$ & $\begin{array}{l}\text { Sleep apnea, apnea, obstructive sleep apnea, } \\
\text { obstructive sleep apnea syndrome }\end{array}$ \\
\hline Snoring & 코골이 & Snoring, snore \\
\hline Restless legs syndrome & 하지불안증후군, 하지불안, 하지불안증 & $\begin{array}{l}\text { Restless legs syndrome, restless leg syndrome, } \\
\text { restless leg, restless legs }\end{array}$ \\
\hline Dementia & 치매, 알츠하이머 치매 & Dementia, Alzheimer dementia, Alzheimer's dementia \\
\hline
\end{tabular}




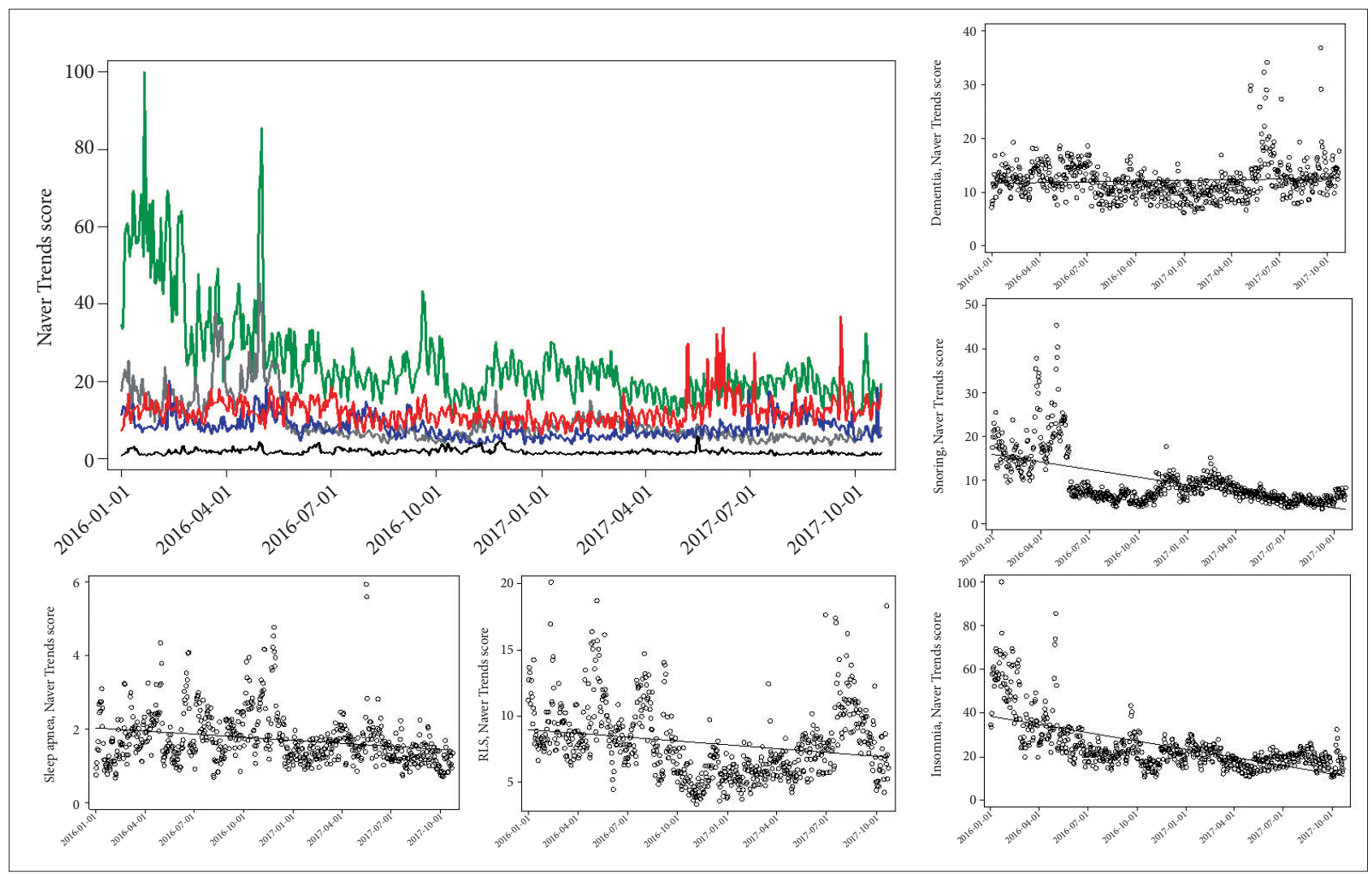

Fig. 1. Evolution of the Naver Trends score for insomnia, sleep apnea, snoring, RLS, and dementia January 2016-October 2017. The continuous line represents the Spearman's correlation between the Naver Trends score and the day. Green line indicates insomnia; black indicates sleep apnea; gray indicates snoring; blue line indicates RLS; red line indicates dementia. RLS: restless legs syndrome.

\section{Age $\geq 40$ years}

The median Naver Trends score of dementia (19.9, IQR, 19.224.0) was higher than that of insomnia (18.4, IQR, 15.4-21.4), RLS (10.0, IQR, 8.2-12.4), snoring (9.4, IQR, 7.3-11.6), and sleep apnea (7.0, IQR, 5.7-9.0).

The median Naver Trends score of insomnia was highest in the age group under 40 years, and those of dementia was highest in age over 40 years, but insomnia remained 2nd high in the age group over 40 years. Between two age groups, each trends score was different significantly ( $p<0.001)$. The trend scores of RLS were higher than those of sleep apnea in all age groups $(\mathrm{p}<$ 0.001) (Fig. 2).

\section{Google Trends Score over January 2004- October 2017}

The overall median Google Trends score of dementia (49, IQR, 45-55) was higher than that of sleep apnea (42, IQR, 4045), insomnia (36, IQR, 34-38), snoring (24, IQR, 21-28), and RLS (23, IQR, 22-27). The Google Trends score of RLS (rho = $-0.55, \mathrm{CI},-0.68$ to $-0.42 ; \mathrm{p}<0.001)$ and sleep apnea (rho $=-0.2$, $\mathrm{CI},-0.38$ to $-0.01 ; \mathrm{p}=0.034$ ) exhibited a decrease over time. That of dementia had displayed a moderately significant increase (rho $=0.59$, CI, 0.45 to $0.74 ; \mathrm{p}<0.001$ ) (Fig. 3).

\section{Google Trends Score over January 2016- October 2017}

The Google Trends score of sleep apnea ( $r h o=0.75, \mathrm{CI}, 0.58$ to $0.91 ; \mathrm{p}<0.001$ ), RLS (rho $=0.66, \mathrm{CI}, 0.40$ to $0.91 ; \mathrm{p}<0.001$ ), insomnia (rho $=0.52, \mathrm{CI}, 0.19$ to $0.85 ; \mathrm{p}=0.002$ ), and dementia (rho $=0.51, \mathrm{CI}, 0.14$ to $0.87 ; \mathrm{p}=0.007$ ) increased over time except that of snoring (rho $=0.18, \mathrm{CI},-0.25$ to $0.61 ; \mathrm{p}=0.412$ ).

\section{DISCUSSION}

In this study, we showed the trends of public interest over some representative sleep disorders by using Internet searching volume of Naver Trends and Google Trends. Age less than 40 years and age over 40 years showed the highest interest in insomnia and dementia in Naver Trends, respectively. Overall, the median Naver Trends score of insomnia was consistently higher than other search terms including dementia.

Insomnia is prevalent disease affecting $5 \%$ of general population and $29.2 \%$ of elderly in Korea. ${ }^{3,4}$ Chronic insomnia increases anxiety, depressive symptoms, and decreases the quality of life, and cause high economic and personal costs. ${ }^{5-7}$ Insomnia is also closely linked to health dissatisfaction. ${ }^{8}$ High prevalence and burden may affect high public awareness and interest 


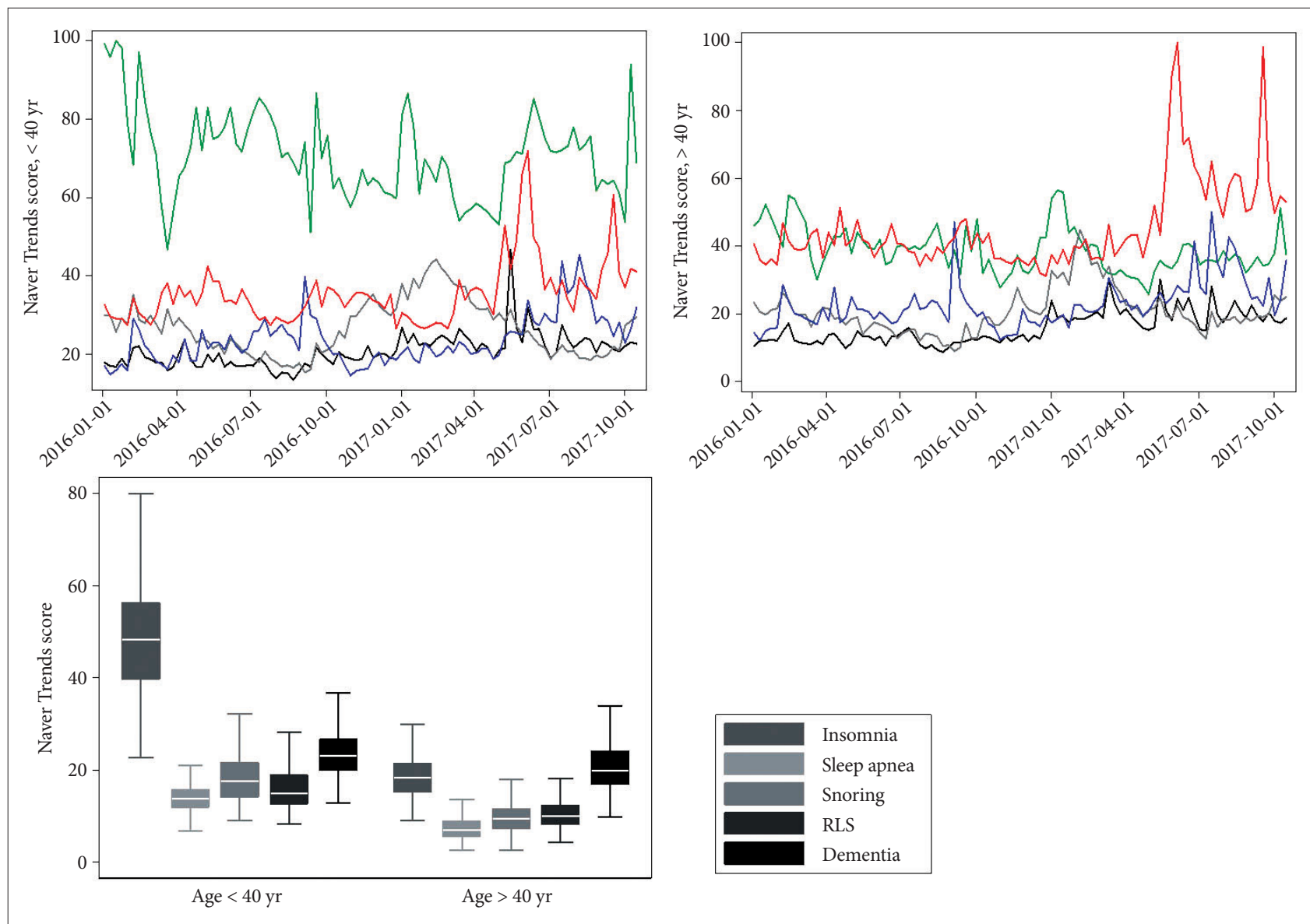

Fig. 2. Evolution of the Naver Trends score for insomnia, sleep apnea, snoring, RLS, and dementia January 2016-October 2017 by age groups of under 40 and over 40. Green line indicates insomnia; black indicates sleep apnea; gray indicates snoring; blue line indicates RLS; red line indicates dementia. The box and whisker plot of median Naver Trends score of sleep disorders and dementia by age group. RLS: restless legs syndrome.

in insomnia through all ages.

Among individuals age 65 or older, the prevalence of dementia is $8.7 \%$, and the median Naver Trends score was the second high in all age groups and highest in age older than 40 . To the contrary, public awareness and interest in other sleep disorders such as sleep apnea and RLS were unexpectedly low in Korea considering the prevalence of disease; obstructive sleep apnea syndrome of $4 \%$ of middle-aged, ${ }^{9}$ habitual snoring of $13.5 \%$ in young male soldiers, ${ }^{10}$ and RLS in $1-7.5 \% .{ }^{11,12}$ The Naver Trends score of sleep disorders decreased over two years but the that of dementia remained unchanged. Though the increasing number of Internet users over a 2-year period in Korea may affect the trends, it is more likely significantly decreased trends of sleep disorders mean decrease of public interest in Korea. To the contrary, The Google Trends score of sleep apnea, insomnia, and RLS consistently increased over time reflecting the public interest in sleep disorders are growing continuously worldwide, though the interpretation of relative search volume should be cautious as the supply and use of Internet worldwide remarkably increased 2004-2017. The search volume on sleep apnea was higher than that of insomnia worldwide.

Together, the differences between Naver and Google Trends imply public interest in sleep disorders in Korea differ from those worldwide. Also, that may indicate there is much room for expanding public attention on sleep disorder in Korea.

A limitation of this study is that we only used Naver Trends to estimate the relative search volumes in Korea because of the lack of search volume in Google Trends using the Korean language. Therefore, though most of the population uses the Naver in Korea, this study cannot estimate for the remaining population who uses other search engines such as Daum and Nate. That also applies to Google Trends worldwide using the English language. Naver and Google Trends are based on data from a subset of the population, those that use the search engine. Consequently, Internet use according to age affects the search volume. According to a survey in 2014 in the United States, 97\% of young adults age 19-27 used the Internet, while only half of elderly older than 65 used the Internet. ${ }^{13}$ This potentially biases sample in specific age groups that may have a higher prevalence of specific sleep disorders. 


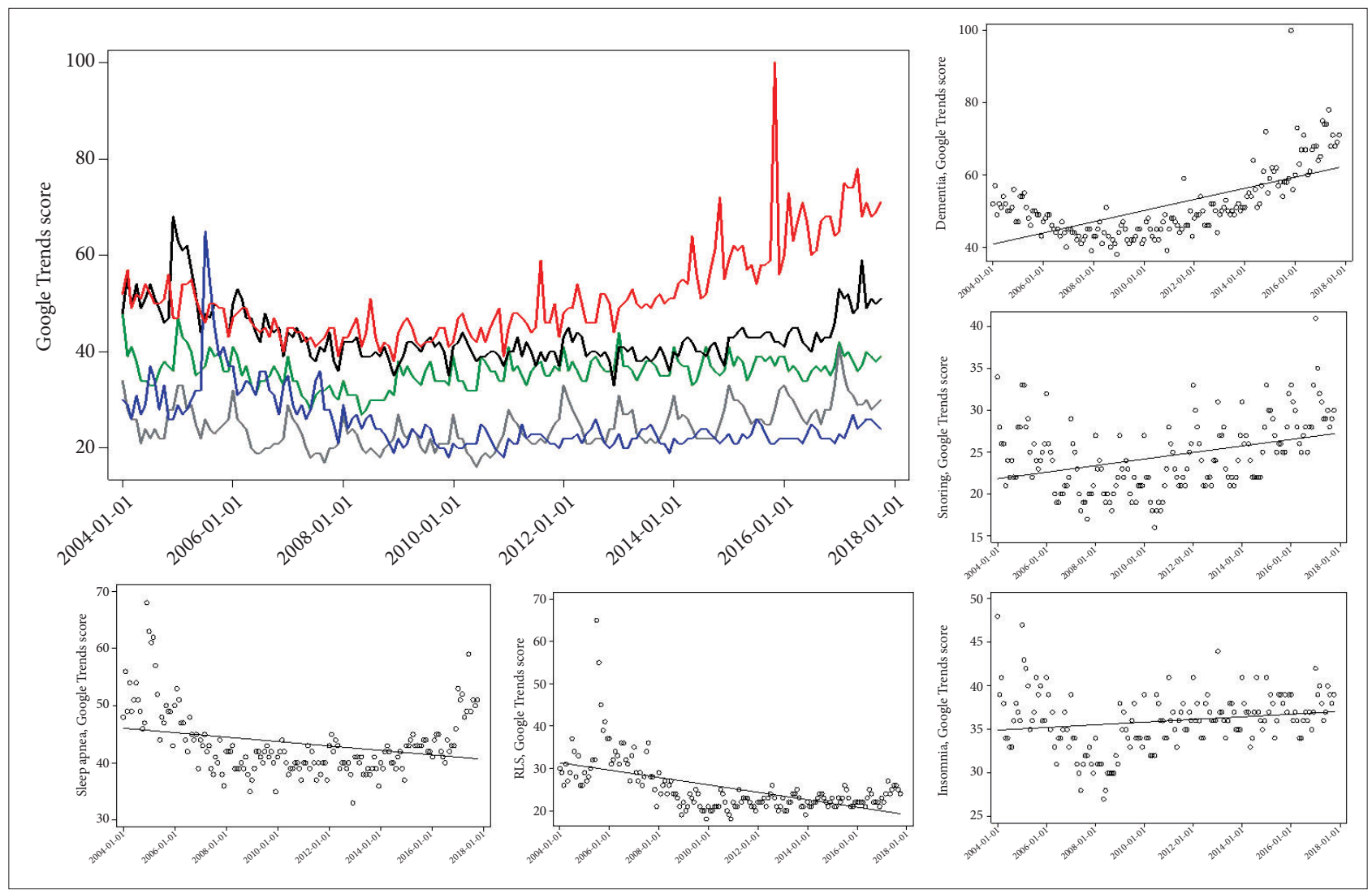

Fig. 3. Evolution of the Google Trends score for insomnia, sleep apnea, snoring, RLS, and dementia January 2004-October 2017. The continuous line represents the Spearman's correlation between the Google Trends score and the month of the year. Green line indicates insomnia; black indicates sleep apnea; gray indicates snoring; blue line indicates RLS; red line indicates dementia. RLS: restless legs syndrome.

In conclusion, these Internet data are convenient, accessible, representative of large populations, and can be used to estimate the public awareness and interest in various medical fields. Internet search data may provide valuable insight into patterns of disease and population behavior. ${ }^{1}$ Our study calls attention to the examination of traffic data to assess the public interest. However, it should be remarked that the quality of the information relating to medical problems that are available online may be highly variable. A notable amount of incorrect information and myths may also be present on the Internet. Considering the increasing tendency of a searching volume of sleep disorders in Google Trends contrary to Naver Trends, sleep societies in Korea should focus on reinforcing the open public activity on sleep disorders. Also, physicians should supply accurate information online as well as in clinics.

\section{Acknowledgments}

This work was supported by grant from Inje University, 2011.

\section{Conflicts of Interest}

The authors have no financial conflicts of interest.

\section{Authors' Contribution}

Conceptualization, investigation, data mining and analysis, interpretation, writing of original draft, review and editing: Ji KH. Review and editing: Kang MR.

\section{REFERENCES}

1. Brownstein JS, Freifeld CC, Madoff LC. Digital disease detection--harnessing the Web for public health surveillance. N Engl J Med 2009;360: 2153-5, 2157.

2. Pelat C, Turbelin C, Bar-Hen A, Flahault A, Valleron A. More diseases tracked by using Google Trends. Emerg Infect Dis 2009;15:1327-8.

3. Kim WH, Kim BS, Kim SK, Chang SM, Lee DW, Cho MJ, et al. Prevalence of insomnia and associated factors in a community sample of elderly individuals in South Korea. Int Psychogeriatr 2013;25:1729-37.

4. Ohayon MM, Hong SC. Prevalence of insomnia and associated factors in South Korea. J Psychosom Res 2002;53:593-600.

5. Taylor DJ, Zimmerman MR, Gardner CE, Williams JM, Grieser EA, Tatum JI, et al. A pilot randomized controlled trial of the effects of cognitive-behavioral therapy for insomnia on sleep and daytime functioning in college students. Behav Ther 2014;45:376-89.

6. Wolk R, Somers VK. Sleep and the metabolic syndrome. Exp Physiol 2007;92:67-78.

7. Morin CM. The nature of insomnia and the need to refine our diagnostic criteria. Psychosom Med 2000;62:483-5.

8. Nomura K, Yamaoka K, Nakao M, Yano E. Impact of insomnia on individual health dissatisfaction in Japan, South Korea, and Taiwan. Sleep 2005;28:1328-32.

9. Kim J, In K, Kim J, You S, Kang K, Shim J, et al. Prevalence of sleep-disordered breathing in middle-aged Korean men and women. Am J Respir Crit Care Med 2004;170:1108-13. 
10. Lee YC, Eun YG, Shin SY, Kim SW. Prevalence of snoring and high risk of obstructive sleep apnea syndrome in young male soldiers in Korea. J Korean Med Sci 2013;28:1373-7.

11. Cho SJ, Hong JP, Hahm BJ, Jeon HJ, Chang SM, Cho MJ, et al. Restless legs syndrome in a community sample of Korean adults: prevalence, impact on quality of life, and association with DSM-IV psychiatric disorders. Sleep 2009;32:1069-76.
12. Cho YW, Shin WC, Yun CH, Hong SB, Kim JH, Allen RP, et al. Epidemiology of restless legs syndrome in Korean adults. Sleep 2008;31:21923.

13. Telfer S, Woodburn J. Let me Google that for you: a time series analysis of seasonality in Internet search trends for terms related to foot and ankle pain. J Foot Ankle Res 2015;8:27. 